\title{
Measurement and Interpretation of Handgrip Strength for Research on Sarcopenia and Osteoporosis
}

\author{
Seung Hoo Lee', Hyun Sik Gong ${ }^{2}$ \\ ${ }^{1}$ Department of Orthopedic Surgery, Regional Rheumatoid and Degenerative Arthritis Center, Chungnam National University Hospital, \\ Chungnam National University School of Medicine, Daejeon; \\ ${ }^{2}$ Department of Orthopedic Surgery, Seoul National University Bundang Hospital, Seoul National University College of Medicine, \\ Seongnam, Korea
}

Corresponding author

Hyun Sik Gong

Department of Orthopedic Surgery, Seoul

National University Bundang Hospital, Seoul

National University College of Medicine,

82 Gumi-ro 173 beon-gil, Bundang-gu,

Seongnam 13620, Korea

Tel: +82-31-787-7198

Fax: +82-31-787-4056

E-mail: hsgong@snu.ac.kr

Received: March 6, 2020

Revised: March 27, 2020

Accepted: March 29, 2020
Handgrip strength (HGS) is associated with several chronic diseases, cognitive decline, length of hospital-stay, and mortality. More importantly, HGS is one of the diagnostic criteria of sarcopenia and gaining attention because of its relevance to bone mineral density (BMD) and osteoporotic fractures. As the measurement of HGS is widely used in clinical practice as well as in research, its accurate measurement and interpretation are becoming more crucial. This review describes how to use different types of dynamometers accurately, the impact of body and arm positions and anthropometric parameters on HGS, the current reference values of HGS for sarcopenia research, and the updates on the relationship between $\mathrm{HGS}$ and $\mathrm{BMD}$ and osteoporotic fractures.

Key Words: Hand strength · Muscle strength · Muscle strength dynamometer · Osteoporosis.Sarcopenia

\section{INTRODUCTION}

Handgrip strength (HGS) is the exertion needed to grasp an object and is necessary for various functional activities in daily life. It is a useful indicator in various clinical situations and can be easily measured at a low cost. HGS is associated with several chronic diseases,[1] cognitive decline,[2] length of hospital-stay,[3] and mortality.[4] More importantly, HGS is one of the major factors for diagnosis of sarcopenia, characterized by progressive generalized loss of skeletal muscle mass and strength with decreased physical performance. Since October 1, 2016, sarcopenia has its own code in the International Classification of Disease, Tenth Revision, Clinical Modification (ICD-10-CM) as M62.84. Also, several studies have revealed the association between sarcopenia and osteoporosis (osteosarcopenia), sharing common risk factors and mechanism.[5-7] In addition, numerous studies show the relationship between HGS and major osteoporotic fractures.[8-11]

As such, accurate measurement and interpretation of HGS is becoming more crucial for sarcopenia and related research. Thus, the purpose of this review was to describe how to use different types of dynamometers accurately, the impact of

\section{Mineral Research}

This is an Open Access article distributed under the terms of the Creative Commons Attribution Non-Commercial License (https://creativecommons.org/licenses/by-nc/4.0/) which permits unrestricted non-commercial use, distribution, and reproduction in any medium, provided the origina work is properly cited.

\section{KSBMR}


body and arm positions and anthropometric parameters on HGS, the current reference values of HGS for sarcopenia research, and the updates on the relationship between HGS and bone mineral density (BMD) and osteoporotic fractures.

\section{TYPES OF DYNAMOMETER FOR HGS MEASUREMENT}

Solgaard et al. [12] suggested 4 characteristics of the ideal dynamometer: (1) reproducible and accurate measurement regardless of high or low HGS; (2) independent of hand size; (3) comfortable for the subjects; (4) small and easy to carry around. Based on these 4 requirements, we review 3 types of handgrip dynamometer, which was frequently used clinically.

\section{Hydraulic type (Jamar and its variants)}

The Jamar and its variants, which are currently most widely used, measure HGS through a sealed hydraulic system (Fig. 1A) and display grip force in pounds and kilograms up to 200 pounds or $90 \mathrm{~kg}$ (Fig. 1B).

Reliability and validity have been proven through several studies.[13-18] It is known that the HGS tends to be measured higher in recent models compared to the earlier mod- el, which might be due to the friction of the handles.[16,19] Also, the earlier models are known to show a greater error rate.[19] Therefore, it may not be appropriate to compare old normative data with recent data.[13,19]

It consists of 2 handles, and 1 handle is curved to fit the hand. It has 5 handle positions for different handle sizes, from 1-3/8 to 3-3/8 inches, in half-inch increments. Generally, the second or third handle provides the strongest HGS, and the second handle is the standard position suggested by the American Society of Hand Therapist (ASHT; Fig. 1A). [20]

The measurement can be difficult or inaccurate in elderly patients with arthritic hand or weak muscle force $[21,22]$ because the weight of the machine is heavy at $1.5 \mathrm{~kg}$ and requires at least 3 to 4 pounds to move the scale.[21] Also, the rigidity of Jamar's handle can cause pain during grip, which can interfere with the measurement of maximal HGS. In such cases, the pneumatic type can be an alternative. $[21,22]$

\section{Pneumatic type (Modified sphygmomanometer and Martin Vigorimeter)}

The pneumatic types use the compressive force to an air-filled bulb or bag (Fig. 2) and display HGS in either millimeter of mercury $(\mathrm{mmHg})$ or pounds per square inch. If a
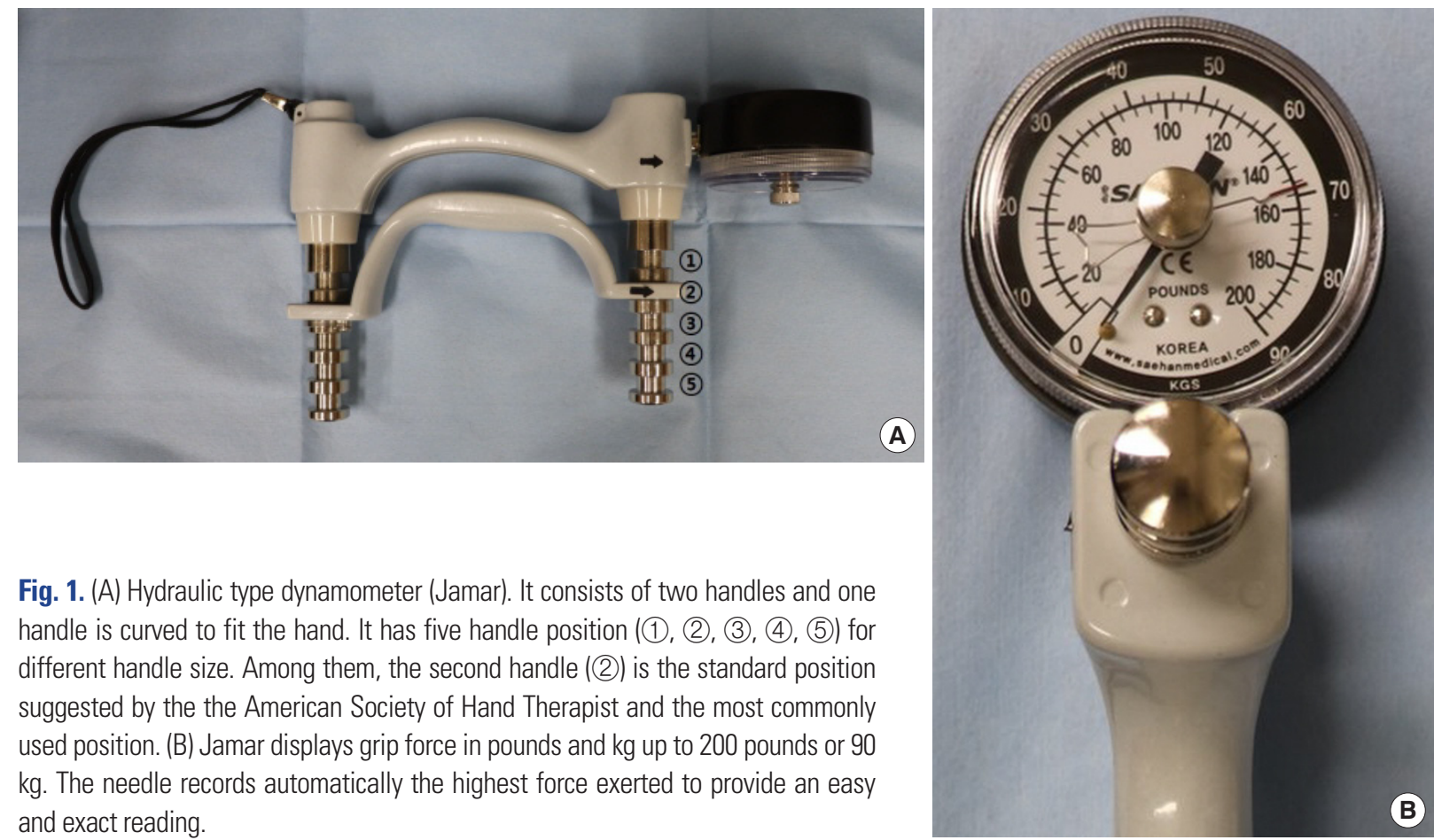

Fig. 1. (A) Hydraulic type dynamometer (Jamar). It consists of two handles and one handle is curved to fit the hand. It has five handle position (1), (2), (3), (4), (5) for different handle size. Among them, the second handle (2) is the standard position suggested by the the American Society of Hand Therapist and the most commonly used position. (B) Jamar displays grip force in pounds and $\mathrm{kg}$ up to 200 pounds or 90 $\mathrm{kg}$. The needle records automatically the highest force exerted to provide an easy and exact reading. 


\section{JBM}

dynamometer is not available due to cost, the HGS can also be measured using the modified sphygmomanometer, which was originally used to measure blood pressure. [23-25] There have been several reports to show an excellent correlation in HGS between conventional handgrip dynamometer and sphygmomanometer.[26,27] In a systematic review, Jamar was the most commonly used one with $22 \%$, followed by a modified sphygmomanometer with $10 \%$.[28]

The test-retest reliability with Martin Vigorimeter was reported to be high (intraclass correlation coefficient [ICC]= $0.92, P<0.001)$, which is comparable to the Jamar dynamometer (ICC $=0.94, P<0.001$ ).[21] Also, a good correla-

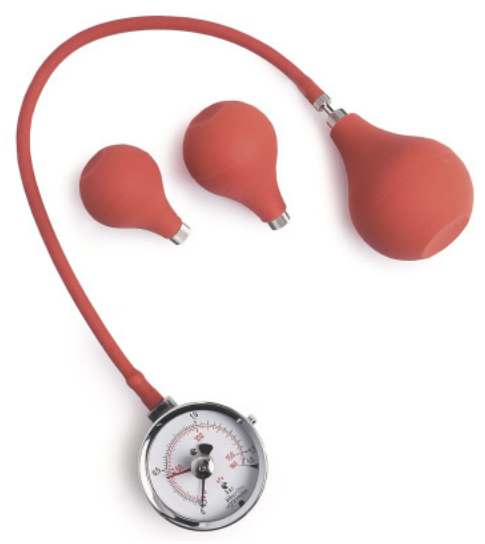

Fig. 2. Pneumatic type dynamometer (Martin Vigorimeter). Three sizes of balloons are available for pediatric and adults.

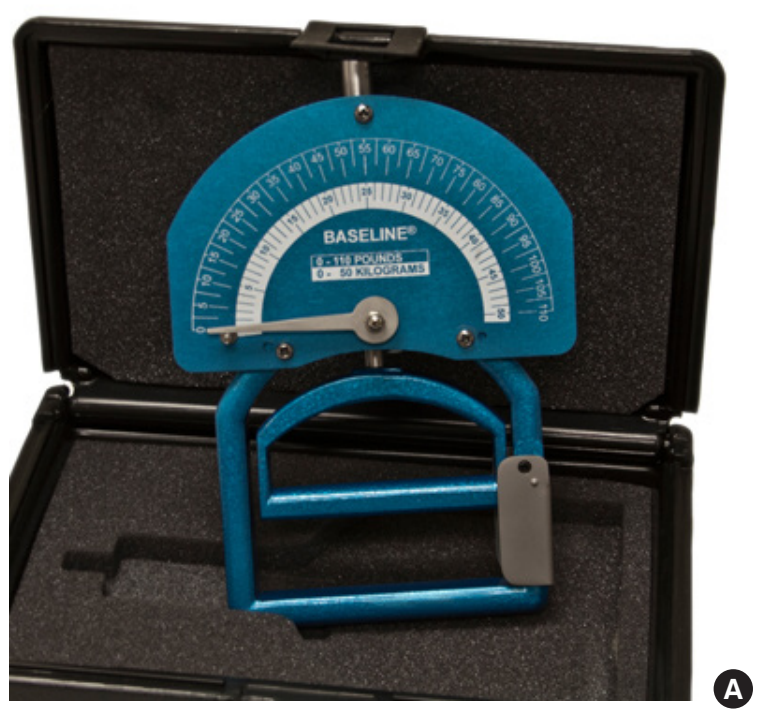

tion is observed between Jamar and Martin Vigorimeter. [29]

As this type measures the pressure by pressing a rubber bulb, patients can press it with less force than other types of dynamometer, which minimizes pain.[21,22] Therefore, it is useful for measuring HGS in old patients with arthritis or sarcopenia or in children with weak HGS.[21,30,31] However, this type can be influenced by hand size.[19] It measures grip pressure, which is dependent on the surface area over which the grip force is transmitted. If the same grip force is applied to the air bulb, the subjects with a bigger hand can generate bigger pressure than smaller ones. Three sizes of balloons are available for pediatric and adults (Fig. 2).

\section{Mechanical type (Smedley type)}

This measures HGS based on the amount of tension generated in a steel spring and displays HGS in kilograms or pounds. It consists of 2 handles, and the distance between the handles can be adjusted depending on the size of the hand (Fig. 3).

Although ASHT recommends using Jamar, Smedley type (e.g., Baseline and Takei, etc.) is commonly used in Asia. Ha et al. [32] describe the methods used for measuring HGS in epidemiologic studies of sarcopenia in Asia. In terms of dynamometer choice, Smedley type is used in 13 studies, and Jamar and its variants are used in 9 studies.[32] Especially, the Smedley type is used in most Japanese population studies.[33]

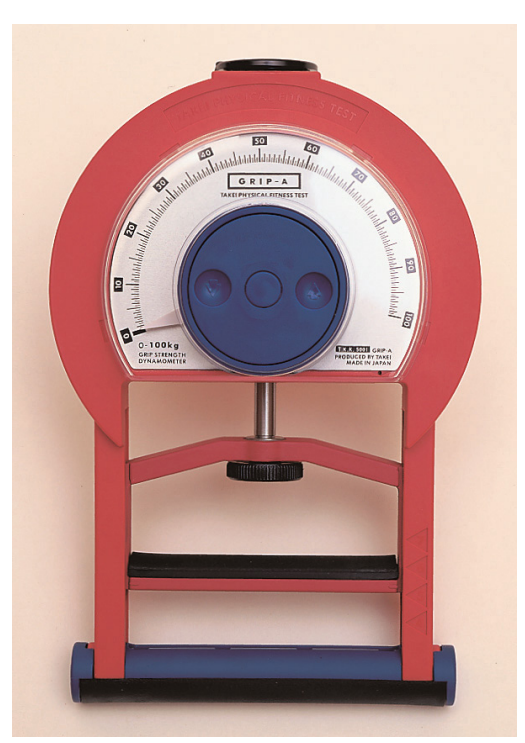

Fig. 3. Mechanical type dynamometer (Smedley type). (A) Baseline. (B) Takei, GRIP-A. 
Test-retest reliability with Smedley has been known to be excellent.[33,34] Also, high correlation coefficients are shown between Jamar and Smedley, although there are significant differences in HGS between the 2 dynamometers.[35] There was a systematic bias with underestimation of HGS by the Smedley type comparing with the Jamar (bias $3.09 \mathrm{~kg}$ for men, and $2.6 \mathrm{~kg}$ for women), resulting in a higher prevalence of weakness.[33] Therefore, comparing the HGS between Smedley and Jamar needs to take this into consideration.

\section{TESTING POSITION FOR HGS MEASUREMENT}

HGS varies depending on the testing position because related muscles have a different optimal length and axis to generate the most powerful grip force. Multiple studies have reported differences in HGS between body and arm positions.

\section{Body position: standing, sitting, and lying down}

Teraoka [36] reported that HGS was weaker when lying down than standing or sitting, and he suggested the influence of gravity as one of its causes. However, Richards [37] reported that there was no significant difference in HGS between the supine and sitting position and suggested that the influence of gravity was not significant. Hillman et al. [38] compared HGS in 3 positions: supine position without arm support, sitting with arm support (armchair), and sitting without arm support. As a result, the HGS was significantly stronger in the sitting without arm support than in the other 2 positions. They attributed the cause to the elbow position rather than to lying or sitting position.

Generally, the sitting position is favored according to the most frequently used protocols (ASHT [20] and Southampton protocol [39]).

\section{Arm position}

There is no consensus on the effect of the arm position to HGS. Some authors reported that HGS was significantly stronger when measured with the elbow in 90 degrees flexion.[40,41] However, another report showed greater HGS with the elbow in full extension.[42] Su et al. [43] reported that the stronger HGS was shown when the shoul- der at 180 degrees of flexion with the elbow in full extension than at shoulder in zero degrees of flexion with 90 degrees of elbow flexion. On the other hand, there was no significant difference in HGS between at 90 and 180 degrees flexion of the shoulder in another report.[41]

The position of the forearm and wrist has been known to affect the HGS. Pryce [44] analyzed the influence of wrist position on HGS, suggesting that ulnar deviation of 0 to 15 degrees and extension posture of 0 to 15 degrees could provide the strongest grip. O'Driscoll and his colleagues [45] showed that the subjects had the strongest HGS at a slight ulnar deviation and 33 to 40 degrees extension of the wrist when they let subjects choose the optimal position to generate the most powerful HGS.

Therefore, it is recommended to compare the HGS in the same testing position to obtain reliable results to minimize the effect. Also, it should be described what body position was applied for comparing results.

\section{ANTHROPOMETRIC PARAMETERS AND HGS}

Height has been known to be associated with HGS by a number of studies. However, there have been contradictory findings about weight and body mass index (BMI). Koopman et al. [46] compared the HGS of the Ghanaian and the Dutch and found that the average grip power of the Dutch was significantly higher than the Ghanaian. However, the height and BMI of Dutch was significantly higher, and differences in body size could largely explain the difference in HGS between them. Spruit et al. [47] found that there was a strong positive correlation between HGS and height in the study from the UK Biobank data. Mitsionis et al. [48] also observed a moderate association between height and HGS in Greek adults. However, they revealed that there was a relatively weak association between weight and HGS. In the study of healthy Caucasian adults, HGS was correlated best with height in both genders, but weight was associated only in men, and BMI was not associated in both.[49]

In a Korean study analyzing 266 subjects older than 65 years old, HGS was associated with height in both men and women, and additionally with BMI in men but not in women.[50] The weight was not associated with HGS in both sexes. However, in a large scale Korean study based on Korean National Health and Nutrition Examination data, wei- 
ght and height were associated with HGS.[51] As the weight increased by $1 \mathrm{~kg}$, the HGS increased by $0.5 \mathrm{~kg}$. As the height increased by $1 \mathrm{~cm}$, the HGS increased by about $0.8 \mathrm{~kg}$. This may be because the former studied only the elderly subject, while the latter targeted the entire age group. The prevalence of sarcopenic obesity is $35 \%$ in men and $48 \%$ in women in elderly Koreans.[52] Fat deposition increased and lean mass decreased in sarcopenic subjects, which may result in low skeletal muscle mass and obesity.[53] Therefore, it is possible that weight and BMI showed a weak or no correlation in elderly subjects in contrast to the study including all adults.

\section{REFERENCE VALUES OF HGS FOR SARCOPENIA RESEARCH}

Sarcopenia refers to a decrease in muscle mass and muscle strength accompanied by the aging process.[54] After introduced by Rosenberg in 1989 [55], there have been many reports about the diagnosis of sarcopenia and its clinical implications, and interest has been growing recently.

Table 1. Cut-off value for low handgrip strength

\begin{tabular}{lcccc}
\hline & $\begin{array}{c}\text { EWGSOP I } \\
{[58]}\end{array}$ & $\begin{array}{c}\text { EWGSOP I } \\
{[32]}\end{array}$ & $\begin{array}{c}\text { AWGS } \\
{[59]}\end{array}$ & $\begin{array}{c}\text { KNHANES } \\
\text { VI [68] }\end{array}$ \\
\hline Method & -2 SD & -2 SD & $\begin{array}{c}\text { lower 20th } \\
\text { percentile }\end{array}$ & $\begin{array}{c}\text { lower 25th } \\
\text { percentile }\end{array}$ \\
Cut-off value (kg) & & & & \\
Male & $<30$ & $<27$ & $<26$ & $<28$ \\
Female & $<20$ & $<16$ & $<18$ & $<16$ \\
\hline
\end{tabular}

EWGSOP, the European Working Group on Sarcopenia in Older People; AWSG, the Asian Working Group for Sarcopenia; KNHANES, the Korea National Health and Nutrition Examination Survey.
As the HGS is simple to measure and has a correlation with strength in other body compartments,[31] it is one of the main factors for diagnosing the sarcopenia.[31,56,57] Indeed, the diagnosis of sarcopenia is based on 3 factors: muscle mass, physical performance, and muscle strength. $[31,56,57]$ Several guidelines suggested a cutoff value of low HGS based on normative data as a representative of low muscle strength (Table 1). We reviewed the definition of low HGS in each guideline and Koreans and related normative data.

\section{The European Working Group on Sarcopenia in Older People I (EWGSOP I)}

Lauretani et al. [58] tested HGS as an indicator of sarcopenia using the data of 1,030 subjects aged from 20 to 102 years from Italy (Table 2). This paper was the basis for the HGS cutoff value in the diagnostic criteria of sarcopenia of EWGSOP I in 2010.[56] They suggested optimal cutoff values for HGS in the identification of subjects walking slower than $0.8 \mathrm{~m} / \mathrm{s}$ and unable to walk for $1 \mathrm{~km}$ without difficulty. The optimal cutoff value was about $30 \mathrm{~kg}$ for men and $20 \mathrm{~kg}$ for women and this suggestion was adopted by EWGSOP I.

\section{The Asian Working Group for Sarcopenia (AWGS)}

In 2014, AWGS suggested a diagnostic algorithm for sarcopenia based on available evidence in Asia.[57] Generally, they take similar approaches to EWGSOP, but they recommended measuring both HGS and gait speed as the screening test. Also, they suggested different cutoff values of low

Table 2. Normative data cited in the European Working Group on Sarcopenia in Older People and the Asian Working Group for Sarcopenia

\begin{tabular}{|c|c|c|c|c|c|c|}
\hline References & Year & Age & $n$ & $\begin{array}{l}\text { Used dynamometer/ } \\
\text { Measurement protocol }\end{array}$ & Mean grip strength & Peak grip strength \\
\hline Lauretani et al. [58] & 2003 & $20-102$ & 1,030 (male: 469) & NA & $\begin{array}{l}\text { Male: } 40.9 \mathrm{~kg} / \\
\text { Female: } 23.2 \mathrm{~kg}\end{array}$ & $\begin{array}{l}\text { Male (2nd decades): } 61.1 \mathrm{~kg} / \\
\text { Female (2nd decades): } 35.6 \mathrm{~kg}\end{array}$ \\
\hline Wu et al. [59] & 2009 & $20-80$ & 482 (male: 244) & $\begin{array}{c}\text { Jamar dynamometer (hydraulic type)/ } \\
\text { ASHT guideline }\end{array}$ & $\begin{array}{l}\text { Male: } 35.0 \mathrm{~kg} / \\
\text { Female: } 21.2 \mathrm{~kg}\end{array}$ & $\begin{array}{l}\text { Male (2nd decades): } 39.5 \mathrm{~kg} / \\
\text { Female (2nd decades): } 25.1 \mathrm{~kg}\end{array}$ \\
\hline Tanimoto et al. [61] & 2012 & $\geq 65$ & 1,158 (male: 364) & $\begin{array}{l}\text { Takei dynamometer } \\
\text { (mechanical type)/NA }\end{array}$ & $\begin{array}{l}\text { Male: } 34.8 \mathrm{~kg} / \\
\text { Female: } 22.1 \mathrm{~kg}\end{array}$ & NA \\
\hline Liu et al. [60] & 2013 & $50-91$ & 532 (male: 282) & $\begin{array}{l}\text { Standing position/Urged to use the } \\
\text { greatest possible force }\end{array}$ & $\begin{array}{l}\text { Male: } 34.4 \mathrm{~kg} / \\
\text { Female: } 21.2 \mathrm{~kg}\end{array}$ & NA \\
\hline Dodds et al. [62] & 2014 & $4-102$ & $\begin{array}{l}60,803 \text { (male: } \\
28,257)\end{array}$ & $\begin{array}{l}\text { Heterogenous dynamometers (mainly } \\
\text { Jamar)/Heterogenous protocol }\end{array}$ & $\begin{array}{l}\text { Male: } 51 \mathrm{~kg} / \\
\text { Female: } 31 \mathrm{~kg}\end{array}$ & $\begin{array}{l}\text { Male (29 to } 39): 38.6 \mathrm{~kg} / \\
\text { Female (26 to } 42): 24.2 \mathrm{~kg}\end{array}$ \\
\hline
\end{tabular}

NA, not available; ASHT, the American Society of Hand Therapist. 
HGS from EWGSOP I because Asians differed from those in Caucasians due to different ethnicities, body size, lifestyle, and cultural environment. For example, Wu et al. [59] measured HGS according to the guidelines of ASHT in 482 Taiwan people, and compare it to consolidated norms acquired from mainly Caucasians. The mean HGS was significantly lower, $25 \%$ in males and $27 \%$ in females. Liu et al. [60] defined low HGS as male $<22.5 \mathrm{~kg}$, female $<14.5 \mathrm{~kg}$ based on the results of Lauretani et al. [58] after being adjusted by the results of Taiwanese norms by Wu and his colleagues [59]. The cutoff values for low HGS recommended by the Japanese population to identify participants unable to walk $1 \mathrm{~km}$ without difficulty were $30.3 \mathrm{~kg}$ and $19.3 \mathrm{~kg}$ for men and women, respectively.[61] Based on these Asian data (Table 2),[59-61] AWGS defined low HGS as $<26 \mathrm{~kg}$ for men and $<18 \mathrm{~kg}$ for women when they used the lower 20th percentile of low HGS of the study population.[57]

\section{The Revised European Working Group on Sarcopenia in Older People (EWGSOP II)}

Recently, EWGSOP suggested revised European consensus on the definition and diagnosis of sarcopenia in 2018. [31] They use low muscle strength (grip strength) as the primary parameter of sarcopenia because muscle strength is presently the most reliable measure of muscle function. Diagnosis is confirmed by additional factors (low muscle quantity or quality). If low physical performance is combined, they called it a severe sarcopenia. There was a change in cutoff points for low HGS, which was $<27 \mathrm{~kg}$ for men and $<16 \mathrm{~kg}$ for women based on normative data from 12 British studies by Dodds and his colleagues [62] (Table 2).
According to the results of their study, HGS increased towards a peak in early adulthood but later decreased from around the age of 50 after a period of plateau. Because this is in line with changes in BMD, the authors suggested that it was reasonable to use T-score to set the cutoff point of low HGS. They recommend using a T-score of -2.5 as a cutoff value because if T-score of -2 was used as a cutoff value, nearly half of subjects aged more than 80 years old were classified into weak HGS. According to their suggested criteria, the cutoff value of HGS is $27 \mathrm{~kg}$ for men and $16 \mathrm{~kg}$ for women. If this criterion is applied, $23.0 \%$ of men and $26.6 \%$ of women would belong to the weak HGS group. This suggestion influenced the cutoff value of HGS in the revised guidelines, and EWGSOPII suggested the cutoff value of HGS as $27 \mathrm{~kg}$ in men and $16 \mathrm{~kg}$ in women. However, they recommend the use of regional normative populations when available because this guideline focused on European populations and the result of HGS depends on stature.

\section{HGS in Koreans}

There have been several normative value measurements of HGS for Korean (Table 3).[51,63-66] However, there were few reports considering the definition of low HGS. Among the data published in Korea, Kim et al. [66] reported the largest normative data with 11,073 subjects (age 10-80 years) based on the Sixth Korea National Health and Nutrition Examination Survey, 2014 to 2015. When they defined the low HGS based on a T-score of $\leq-2$ standard deviation, the cutoff value was $33 \mathrm{~kg}$ in males and $20 \mathrm{~kg}$ in females. However, when this cutoff was applied, about $20 \%$ of subjects at age 65 to 69 years had low HGS. Whereas, the low-

Table 3. Normative data of hand grip strength in Koreans

\begin{tabular}{|c|c|c|c|c|c|c|}
\hline References & Year & Age & $\mathrm{n}$ & Measurement protocol & Mean grip strength & Peak grip strength \\
\hline Lee et al. [63] & 1995 & $20-74$ & 479 (male: 248) & $\begin{array}{l}\text { Jamar dynamometer (hydraulic type), handle setting: } \\
\text { level II, shoulder: adducted and neutrally rotated, } \\
\text { elbow: flexed at } 90^{\circ} \text {, forearm and wrist: neutral }\end{array}$ & $\begin{array}{l}\text { Male: } 40.8 \mathrm{~kg} / \\
\text { Female: } 25.1 \mathrm{~kg}\end{array}$ & $\begin{array}{l}\text { Male (2nd decades): } \\
43.9 \mathrm{~kg} / \text { Female (2nd } \\
\text { decades): } 27.3 \mathrm{~kg}\end{array}$ \\
\hline Han et al. [64] & 2009 & $10-80$ & 515 (male: 234) & $\begin{array}{l}\text { Jamar dynamometer (hydraulic type), handle setting: } \\
\text { level II, shoulder: adducted and neutrally rotated, } \\
\text { elbow: flexed at } 90^{\circ} \text { forearm and wrist: neutral }\end{array}$ & $\begin{array}{l}\text { Male: } 41.77 \mathrm{~kg} / \\
\text { Female: } 25.2 \mathrm{~kg}\end{array}$ & $\begin{array}{l}\text { Male (3rd decades): } \\
48.79 \mathrm{~kg} / \text { Female (3rd } \\
\text { decades): } 28.22 \mathrm{~kg}\end{array}$ \\
\hline Shim et al. [65] & 2013 & $13-77$ & 336 (male: 137) & $\begin{array}{l}\text { Jamar dynamometer (hydraulic type), handle setting: } \\
\mathrm{NA} \text {, shoulder: adducted and neutrally rotated, elbow: } \\
\text { flexed at } 90^{\circ} \text {, forearm: neutral, wrist: between } 0^{\circ} \text { and } \\
\qquad 15^{\circ} \text { of ulnar deviation }\end{array}$ & $\begin{array}{l}\text { Male: } 42.3 \mathrm{~kg} / \\
\text { Female: } 26.5 \mathrm{~kg}\end{array}$ & $\begin{array}{l}\text { Male (2nd decades): } \\
46.9 \mathrm{~kg} / \text { Female }(2 \mathrm{nd} \\
\text { decades): } 27.5 \mathrm{~kg}\end{array}$ \\
\hline Kim et al. [66] & 2018 & $10-80$ & $\begin{array}{c}11,073 \text { (male: } \\
5,054)\end{array}$ & $\begin{array}{c}\text { Takei dynamometer (mechanical type), handle setting: } \\
\text { adjusted the grip size for each hand, shoulder: neural } \\
\text { position, arm: at the side, elbow: fully extended, wrist: } \\
\text { neutral }\end{array}$ & $\begin{array}{l}\text { Male: } 40.3 \mathrm{~kg} / \\
\text { Female: } 25.5 \mathrm{~kg}\end{array}$ & $\begin{array}{l}\text { Male (35 to } 39): \\
47.2 \mathrm{~kg} / \text { Female } \\
\text { (35 to } 39): 28.7 \mathrm{~kg}\end{array}$ \\
\hline
\end{tabular}


est quintile of maximal HGS for age 70 years or older was approximately $28 \mathrm{~kg}$ for males and $16 \mathrm{~kg}$ for females, with similar cutoff values as other guidelines. To verify the Korean cutoff value for low HGS, further studies should be performed with appropriate protocols.

\section{RELATIONSHIP BETWEEN HGS AND BMD/ MAJOR OSTEOPOROTIC FRACTURES}

\section{HGS and BMD}

Several reports have revealed that there was a significant correlation between HGS and BMD of the bones adjacent to the muscles related to grip.[67-69] Osei-Hyiaman et al. [67] studied 1,168 menopausal women and found that there was a significant correlation between HGS and $B M D$ of the metacarpal index $(r=0.2474, P<0.001)$. Di Monaco et al. [68] reported that HGS correlated with BMD of the distal radius when they analyzed 120 postmenopausal women ( $r=0.576, P<0.001)$. Hasegawa et al. [69] found that BMD of the distal radius was more associated with HGS than with cross-sectional muscle area. Kaya et al. [70] found that hand BMD was significantly correlated with HGS in men but not in women aged 19 to 50 years, which might be masked by normal levels of estrogen in women.[71]

However, there have been conflicting reports on whether HGS is related to BMDs of non-adjacent bones.[50,70-81] Zimmermann et al. [73] reported that HGS in postmenopausal women was not associated with vertebral BMD but only correlated with BMD of the femur, whereas Foley et al. [74] found no correlation between the HGS and femoral BMD. Aydin et al. [75] suggested that HGS was the best predictor of regional BMD, but it was not related to lumbar or femoral neck BMD when they analyzed 200 male patients. Lee et al. [50] found that BMD of the lumbar and proximal femur was not associated with HGS in elderly Koreans. On the other hand, there have been many studies that support the association. Kritz-Silverstein and BarrettConnor [72] found that HGS was associated not only with BMDs of adjacent bones (wrist and midshaft radius) but also with BMDs of distant bones (spine and hip) in 649 menopausal women. Nasri et al. [76] revealed that HGS was correlated with the BMD of the whole body and spine by comparing 50 athletes with 30 sedentary subjects. Izumotani et al. [77] and Bevier et al. [78] also reported a correlation between HGS and BMD of the lumbar spine in healthy middle-aged men and postmenopausal women. In addition, Luo et al. [81] revealed that HGS was associated with BMD of non-adjacent bone by analyzing 1,850 subjects from the National Health and Nutrition Examination Survey of US population and suggested that HGS of dominant hand can be an indicator of BMD. Further studies in a larger population or a meta-analysis would be necessary to have a conclusive result on this issue.

\section{HGS and hip fractures}

Hip fractures are a serious health problem [82-84] and have relatively high mortality rates, with $18 \%$ to $33 \%$ at one year.[85] Hip fractures cause permanent disability in about $20 \%$ of survivors, and only about $40 \%$ of them are known to recover their function to pre-injury level.[85] Therefore, the need for prognostic factors has been emerging, which could predict the mortality rate and the degree of functional recovery after hip fractures.[86,87] Among these, the role of muscle strength is drawing attention, and lower muscle strength is known as one of the prognostic factors.[88-90] HGS is known as a good indicator of overall muscle strength,[56] so there are multiple studies on its prognostic value in patients with hip fractures.

Most studies have reported relatively low HGS in hip fracture patients. Coupland et al. [91] found that hip fracture risk was significantly increased with a decline in HGS when comparing hip fracture patients aged more than 50 years old to age and sex-matched controls. Bean et al. [92] reported that hip fracture patients showed significantly lower HGS than controls in a study comparing 50 women with hip fracture to age-matched controls. Cawthon et al. [93] found that hip fracture risk was increasing in men who were unable to complete the HGS measure, which suggested significant muscle weakness. Kärkkäinen et al. [8] that there was a correlation between decreased HGS and risk of hip fracture in a prospective study of 2,928 post-menopausal women. Denk et al. [9] performed a systematic review about the association between decreased HGS and hip fracture with 6 case-control and 5 cohort studies. He found that weak HGS was associated with increased hip fracture risk in all included studies.[9]

There have been several studies about the relationship between HGS and recovery after hip fracture.[88-90,94-97] Wehren et al. [89] reported that functional outcomes showed a moderate correlation (range, 0.37-0.42) with HGS, while 
the correlation was minimal with bone or body composition in 205 hip fracture women. Di Monaco et al. [88] suggested that HGS before rehabilitation was significantly associated with the ability to perform daily activities at the end of rehabilitation in 123 hip fractured women. Álvarez et al. [95] found that there was a significant association between HGS at admission and Barthel index and functional recovery at 3 months. Savino et al. [96] found that the patients with higher HGS showed higher probabilities of walking recovery than those with lower HGS after hip fractures at a 1-year follow-up in 504 patients. Hershkovitz et al. [87] reported a significant correlation between HGS and functional outcomes in 373 post-hip fracture patients. These results suggest that HGS measurement could be a tool for screening patients who require more aggressive rehabilitation.

\section{HGS and vertebral fractures}

There were conflicting reports about the association between vertebral fracture and HGS. Samelson et al. [11] studied potential risk factors of vertebral fracture in middleaged people. They found that HGS did not associate with the risk of vertebral fracture. Kärkkäinen et al. [8] found that a clinical vertebral fracture was not associated with HGS in a prospective study based on 2,928 postmenopausal women with an 8-year follow-up. However, Cawthon et al. [98] fount that poor performance on HGS was associated with an increased risk of incident radiographic vertebral fracture, although clinical vertebral fracture was not associated based on the data from the Osteoporotic Fractures in Men study in the US. Also, it was revealed that low HGS was associated with an increased clinical vertebral fracture risk over a 15-year period in the study based on 1,342 Japanese postmenopausal women with a hazard ratio of 4.55 . [10]

\section{CONCLUSIONS}

Numerous studies have been published about HGS. For proper interpretation of these studies, it is imperative to understand that there can be variations in HGS by the use of different type of dynamometers, body and arm positions, and anthropometric parameters. HGS is one of the criteria for diagnosis of sarcopenia and the reference value can change according to the guidelines targeting relevant study populations. Studies suggest a positive relationship between HGS and BMD of the bones of the hand and forearm, but there are conflicting results on the relationship between HGS and BMDs of non-adjacent bones. Additionally, most studies have reported relatively low HGS in hip fracture patients, but the relationship between HGS and vertebral fractures is not definite. Future studies with accurate measurement and interpretation of HGS may reveal more beneficial information on sarcopenia and related areas.

\section{DECLARATIONS}

\section{Acknowledgments}

This work was supported by the National Research Foundation of Korea (NRF) grant funded by the Korean government (Ministry of Science and ICT) (Grant No. 2020R1A2C 1005778). Thanks for the photographs of dynamometers to Fabrication Enterprises Inc., Takei Scientific Instruments Co., Ltd., and Albert Waeschle Group.

\section{Ethics approval and consent to participate Not applicable.}

\section{Conflict of interest}

No potential conflict of interest relevant to this article was reported.

\section{ORCID}

Seung Hoo Lee https://orcid.org/0000-0001-8260-4358

Hyun Sik Gong https://orcid.org/0000-0003-4028-1559

\section{REFERENCES}

1. Rantanen T, Guralnik JM, Sakari-Rantala R, et al. Disability, physical activity, and muscle strength in older women: the Women's Health and Aging Study. Arch Phys Med Rehabil 1999;80:130-5.

2. Alfaro-Acha A, Al Snih S, Raji MA, et al. Handgrip strength and cognitive decline in older Mexican Americans. J Gerontol A Biol Sci Med Sci 2006;61:859-65.

3. Keevil V, Mazzuin Razali R, Chin AV, et al. Grip strength in a cohort of older medical inpatients in Malaysia: a pilot study to describe the range, determinants and association with length of hospital stay. Arch Gerontol Geriatr 2013;56:155-9.

4. Cooper R, Kuh D, Hardy R. Objectively measured physical 
capability levels and mortality: systematic review and meta-analysis. BMJ 2010;341:c4467.

5. Hirschfeld HP, Kinsella R, Duque G. Osteosarcopenia: where bone, muscle, and fat collide. Osteoporos Int 2017;28:278190.

6. Hassan EB, Duque G. Osteosarcopenia: A new geriatric syndrome. Aust Fam Physician 2017;46:849-53.

7. Paintin J, Cooper C, Dennison E. Osteosarcopenia. Br J Hosp Med (Lond) 2018;79:253-8.

8. Kärkkäinen M, Rikkonen T, Kröger $H$, et al. Association between functional capacity tests and fractures: an eightyear prospective population-based cohort study. Osteoporos Int 2008;19:1203-10.

9. Denk K, Lennon S, Gordon S, et al. The association between decreased hand grip strength and hip fracture in older people: A systematic review. Exp Gerontol 2018;111:1-9.

10. Kamiya K, Kajita E, Tachiki T, et al. Association between hand-grip strength and site-specific risks of major osteoporotic fracture: Results from the Japanese Populationbased Osteoporosis Cohort Study. Maturitas 2019;130:1320.

11. Samelson EJ, Hannan MT, Zhang Y, et al. Incidence and risk factors for vertebral fracture in women and men: $25-$ year follow-up results from the population-based Framingham study. J Bone Miner Res 2006;21:1207-14.

12. Solgaard S, Kristiansen B, Jensen JS. Evaluation of instruments for measuring grip strength. Acta Orthop Scand 1984;55:569-72.

13. Härkönen R, Harju R, Alaranta H. Accuracy of the Jamar dynamometer. J Hand Ther 1993;6:259-62.

14. Mathiowetz V, Weber K, Volland G, et al. Reliability and validity of grip and pinch strength evaluations. J Hand Surg Am 1984;9:222-6.

15. Niebuhr BR, Marion R, Fike ML. Reliability of grip strength assessment with the computerized Jamar dynamometer. Occup Ther J Res 1994;14:3-18.

16. Flood-Joy M, Mathiowetz V. Grip-strength measurement: A comparison of three Jamar dynamometers. Occup Ther J Res 1987;7:235-43.

17. Lusardi MM, Bohannon RW. Hand grip strength: Comparability of measurements obtained with a jamar dynamometer and a modified sphygmomanometer. J Hand Ther 1991;4:117-22.

18. Hamilton A, Balnave R, Adams R. Grip strength testing reliability. J Hand Ther 1994;7:163-70.
19. Richards L, Palmiter-Thomas P. A critical review of tools, methods, and clinical utility for grip strength measurement. Crit Rev Phys Rehabil Med 2017;29:315-40.

20. MacDermid J, Solomon G, Valdes K, et al. Clinical assessment recommendations. 3rd ed. Mount Laurel, NJ: American Society of Hand Therapists; 2015.

21. Sipers WM, Verdijk LB, Sipers SJ, et al. The Martin Vigorimeter represents a reliable and more practical tool than the Jamar dynamometer to assess handgrip strength in the geriatric patient. J Am Med Dir Assoc 2016;17:466.e1-7.

22. De Dobbeleer L, Theou O, Beyer I, et al. Martin Vigorimeter assesses muscle fatigability in older adults better than the Jamar Dynamometer. Exp Gerontol 2018;111:65-70.

23. Pincus T, Callahan LF, Sale WG, et al. Severe functional declines, work disability, and increased mortality in seventyfive rheumatoid arthritis patients studied over nine years. Arthritis Rheum 1984;27:864-72.

24. Milne JS, Maule MM. A longitudinal study of handgrip and dementia in older people. Age Ageing 1984;13:42-8.

25. Pincus T, Brooks RH, Callahan LF. Prediction of long-term mortality in patients with rheumatoid arthritis according to simple questionnaire and joint count measures. Ann Intern Med 1994;120:26-34.

26. Martins JC, Teixeira-Salmela LF, Castro e Souza LA, et al. Reliability and validity of the modified sphygmomanometer test for the assessment of strength of upper limb muscles after stroke. J Rehabil Med 2015;47:697-705.

27. Souza LACe, Martins JC, Teixeira-Salmela LF, et al. Evaluation of muscular strength with the modified sphygmomanometer test: a review of the literature. Fisioter Mov 2013; 26:437-52.

28. Mafi P, Mafi R, Hindocha S, et al. A systematic review of dynamometry and its role in hand trauma assessment. Open Orthop J 2012;6:95-102.

29. Desrosiers J, Hebert R, Bravo G, et al. Comparison of the Jamar dynamometer and the Martin vigorimeter for grip strength measurements in a healthy elderly population. Scand J Rehabil Med 1995;27:137-43.

30. Molenaar HM, Zuidam JM, Selles RW, et al. Age-specific reliability of two grip-strength dynamometers when used by children. J Bone Joint Surg Am 2008;90:1053-9.

31. Cruz-Jentoft AJ, Bahat G, Bauer J, et al. Sarcopenia: revised European consensus on definition and diagnosis. Age Ageing 2019;48:601.

32. Ha YC, Hwang SC, Song SY, et al. Hand grip strength mea- 
surement in different epidemiologic studies using various methods for diagnosis of sarcopenia: a systematic review. Eur Geriatr Med 2018;9:277-88.

33. Kim M, Shinkai S. Prevalence of muscle weakness based on different diagnostic criteria in community-dwelling older adults: A comparison of grip strength dynamometers. Geriatr Gerontol Int 2017;17:2089-95.

34. Stratford PW, Norman GR, McIntosh JM. Generalizability of grip strength measurements in patients with tennis elbow. Phys Ther 1989;69:276-81.

35. Guerra RS, Amaral TF. Comparison of hand dynamometers in elderly people. J Nutr Health Aging 2009;13:907-12.

36. Teraoka T. Studies on the peculiarity of grip strength in relation to body positions and aging. Kobe J Med Sci 1979; 25:1-17.

37. Richards LG. Posture effects on grip strength. Arch Phys Med Rehabil 1997;78:1154-6.

38. Hillman TE, Nunes QM, Hornby ST, et al. A practical posture for hand grip dynamometry in the clinical setting. Clin Nutr 2005;24:224-8.

39. Roberts HC, Denison HJ, Martin HJ, et al. A review of the measurement of grip strength in clinical and epidemiological studies: towards a standardised approach. Age Ageing 2011;40:423-9.

40. Mathiowetz V, Rennells C, Donahoe L. Effect of elbow position on grip and key pinch strength. J Hand Surg Am 1985;10:694-7.

41. De $S$, Sengupta P, Maity P, et al. Effect of body posture on hand grip strength in adult Bengalee population. J Exerc Sci Physiother 2011;7:79-88.

42. Oxford KL. Elbow positioning for maximum grip performance. J Hand Ther 2000;13:33-6.

43. Su CY, Lin JH, Chien TH, et al. Grip strength in different positions of elbow and shoulder. Arch Phys Med Rehabil 1994;75:812-5

44. Pryce JC. The wrist position between neutral and ulnar deviation that facilitates the maximum power grip strength. J Biomech 1980;13:505-11.

45. O'Driscoll SW, Horii E, Ness R, et al. The relationship between wrist position, grasp size, and grip strength. J Hand Surg Am 1992;17:169-77.

46. Koopman JJ, van Bodegom D, van Heemst D, et al. Handgrip strength, ageing and mortality in rural Africa. Age Ageing 2015;44:465-70.

47. Spruit MA, Sillen MJ, Groenen MT, et al. New normative values for handgrip strength: results from the UK Biobank. J Am Med Dir Assoc 2013;14:775.e5-11.

48. Mitsionis G, Pakos EE, Stafilas KS, et al. Normative data on hand grip strength in a Greek adult population. Int Orthop 2009;33:713-7.

49. Günther CM, Bürger A, Rickert M, et al. Grip strength in healthy caucasian adults: reference values. J Hand Surg Am 2008;33:558-65.

50. Lee JE, Kim KW, Paik NJ, et al. Evaluation of factors influencing grip strength in elderly koreans. J Bone Metab 2012; 19:103-10.

51. Lim SH, Kim YH, Lee JS. Normative data on grip strength in a population-based study with adjusting confounding factors: Sixth Korea national health and nutrition examination survey (2014-2015). Int J Environ Res Public Health 2019;16:E2235.

52. Jang HC. Recent progression in sarcopenia and sarcopenic obesity. J Korean Geriatr Soc 2011;15:1-7.

53. Sternfeld B, Ngo L, Satariano WA, et al. Associations of body composition with physical performance and self-reported functional limitation in elderly men and women. Am J Epidemiol 2002;156:110-21.

54. Delmonico MJ, Harris TB, Visser M, et al. Longitudinal study of muscle strength, quality, and adipose tissue infiltration. Am J Clin Nutr 2009;90:1579-85.

55. Rosenberg IH. Epidemiologic and methodologic problems in determining nutritional status of older persons: Summary comments. Am J Clin Nutr 1989;50:1231-3.

56. Cruz-Jentoft AJ, Baeyens JP, Bauer JM, et al. Sarcopenia: European consensus on definition and diagnosis: Report of the European Working Group on Sarcopenia in Older People. Age Ageing 2010;39:412-23.

57. Chen LK, Liu LK, Woo J, et al. Sarcopenia in Asia: consensus report of the Asian Working Group for Sarcopenia. J Am Med Dir Assoc 2014;15:95-101.

58. Lauretani F, Russo CR, Bandinelli S, et al. Age-associated changes in skeletal muscles and their effect on mobility: an operational diagnosis of sarcopenia. J Appl Physiol (1985) 2003:95:1851-60.

59. Wu SW, Wu SF, Liang HW, et al. Measuring factors affecting grip strength in a Taiwan Chinese population and a comparison with consolidated norms. Appl Ergon 2009; 40:811-5.

60. Liu LK, Lee WJ, Liu CL, et al. Age-related skeletal muscle mass loss and physical performance in Taiwan: implica- 


\section{$\mathrm{JBM}$}

tions to diagnostic strategy of sarcopenia in Asia. Geriatr Gerontol Int 2013;13:964-71.

61. Tanimoto Y, Watanabe M, Sun W, et al. Association between sarcopenia and higher-level functional capacity in daily living in community-dwelling elderly subjects in Japan. Arch Gerontol Geriatr 2012;55:e9-13.

62. Dodds RM, Syddall HE, Cooper R, et al. Grip strength across the life course: normative data from twelve British studies. PLoS One 2014;9:e113637.

63. Lee KS, Woo KJ, Shim JH, et al. The clinical study of grip and pinch strength in normal Korean adult. J Korean Orthop Assoc 1995;30:1589-97.

64. Han SH, Nam KS, Ahn TK, et al. Analysis of grip and pinch strength in Korean people. J Korean Orthop Assoc 2009; 44:219-25.

65. Shim JH, Roh SY, Kim JS, et al. Normative measurements of grip and pinch strengths of 21st century Korean population. Arch Plast Surg 2013;40:52-6.

66. Kim M, Won CW, Kim M. Muscular grip strength normative values for a Korean population from the Korea National Health and Nutrition Examination Survey, 2014-2015. PLoS One 2018;13:e0201275.

67. Osei-Hyiaman D, Ueji M, Toyokawa S, et al. Influence of grip strength on metacarpal bone mineral density in postmenopausal Japanese women: a cross-sectional study. Calcif Tissue Int 1999;64:263-6.

68. Di Monaco M, Di Monaco R, Manca M, et al. Handgrip strength is an independent predictor of distal radius bone mineral density in postmenopausal women. Clin Rheumatol 2000;19:473-6.

69. Hasegawa Y, Schneider P, Reiners C. Age, sex, and grip strength determine architectural bone parameters assessed by peripheral quantitative computed tomography (pQCT) at the human radius. J Biomech 2001;34:497-503.

70. Kaya A, Ozgocmen S, Ardicoglu O, et al. Relationship between grip strength and hand bone mineral density in healthy adults. Arch Med Res 2005;36:603-6.

71. Sinaki M, Fitzpatrick LA, Ritchie CK, et al. Site-specificity of bone mineral density and muscle strength in women: jobrelated physical activity. Am J Phys Med Rehabil 1998;77: 470-6.

72. Kritz-Silverstein D, Barrett-Connor E. Grip strength and bone mineral density in older women. J Bone Miner Res 1994;9:45-51.

73. Zimmermann CL, Smidt GL, Brooks JS, et al. Relationship
Handgrip Strength in Sarcopenia and Osteoporosis

of extremity muscle torque and bone mineral density in postmenopausal women. Phys Ther 1990;70:302-9.

74. Foley KT, Owings TM, Pavol MJ, et al. Maximum grip strength is not related to bone mineral density of the proximal femur in older adults. Calcif Tissue Int 1999;64:291-4.

75. Aydin G, Atalar E, Keleş l, et al. Predictive value of grip strength for bone mineral density in males: site specific or systemic? Rheumatol Int 2006;27:125-9.

76. Nasri R, Hassen Zrour S, Rebai H, et al. Grip strength is a predictor of bone mineral density among adolescent combat sport athletes. J Clin Densitom 2013;16:92-7.

77. Izumotani K, Hagiwara S, Izumotani T, et al. Risk factors for osteoporosis in men. J Bone Miner Metab 2003;21:86-90.

78. Bevier WC, Wiswell RA, Pyka G, et al. Relationship of body composition, muscle strength, and aerobic capacity to bone mineral density in older men and women. J Bone Miner Res 1989;4:421-32.

79. Cauley JA, Fullman RL, Stone KL, et al. Factors associated with the lumbar spine and proximal femur bone mineral density in older men. Osteoporos Int 2005;16:1525-37.

80. McGrath RP, Kraemer WJ, Vincent BM, et al. Muscle strength Is protective against osteoporosis in an ethnically diverse sample of adults. J Strength Cond Res 2017;31:2586-9.

81. Luo $Y$, Jiang $K$, He M. Association between grip strength and bone mineral density in general US population of $\mathrm{NH}$ ANES 2013-2014. Arch Osteoporos 2020;15:47.

82. Cooper C, Atkinson EJ, Jacobsen SJ, et al. Population-based study of survival after osteoporotic fractures. Am J Epidemiol 1993;137:1001-5.

83. Fisher ES, Baron JA, Malenka DJ, et al. Hip fracture incidence and mortality in New England. Epidemiology 1991;2:11622.

84. Parker MJ, Anand JK. What is the true mortality of hip fractures? Public Health 1991;105:443-6.

85. Magaziner J, Fredman L, Hawkes W, et al. Changes in functional status attributable to hip fracture: a comparison of hip fracture patients to community-dwelling aged. Am J Epidemiol 2003;157:1023-31.

86. Xu BY, Yan S, Low LL, et al. Predictors of poor functional outcomes and mortality in patients with hip fracture: a systematic review. BMC Musculoskelet Disord 2019;20:568.

87. Hershkovitz A, Yichayaou B, Ronen A, et al. The association between hand grip strength and rehabilitation outcome in post-acute hip fractured patients. Aging Clin Exp Res 2019;31:1509-16. 
88. Di Monaco M, Castiglioni C, De Toma E, et al. Handgrip strength but not appendicular lean mass is an independent predictor of functional outcome in hip-fracture women: a short-term prospective study. Arch Phys Med Rehabil 2014;95:1719-24.

89. Wehren LE, Hawkes WG, Hebel JR, et al. Bone mineral density, soft tissue body composition, strength, and functioning after hip fracture. J Gerontol A Biol Sci Med Sci 2005; 60:80-4.

90. Beloosesky Y, Weiss A, Manasian M, et al. Handgrip strength of the elderly after hip fracture repair correlates with functional outcome. Disabil Rehabil 2010;32:367-73.

91. Coupland C, Wood D, Cooper C. Physical inactivity is an independent risk factor for hip fracture in the elderly. J Epidemiol Community Health 1993;47:441-3.

92. Bean N, Bennett KM, Lehmann AB. Habitus and hip fracture revisited: skeletal size, strength and cognition rather than thinness? Age Ageing 1995;24:481-4.

93. Cawthon PM, Fullman RL, Marshall L, et al. Physical performance and risk of hip fractures in older men. J Bone Miner
Res 2008:23:1037-44.

94. Di Monaco M, Castiglioni C. Weakness and low lean mass in women with hip fracture: Prevalence according to the FNIH criteria and association with the short-term functional recovery. J Geriatr Phys Ther 2017;40:80-5.

95. Álvarez MN, Bonnardeaux PLD, Thuissard IJ, et al. Grip strength and functional recovery after hip fracture: An observational study in elderly population. Eur Geriatr Med 2016; 7:556-60.

96. Savino E, Martini E, Lauretani F, et al. Handgrip strength predicts persistent walking recovery after hip fracture surgery. Am J Med 2013;126:1068-75.e1.

97. Di Monaco M, Castiglioni C, De Toma E, et al. Handgrip strength is an independent predictor of functional outcome in hip-fracture women: a prospective study with 6-month follow-up. Medicine (Baltimore) 2015;94:e542.

98. Cawthon PM, Blackwell TL, Marshall LM, et al. Physical performance and radiographic and clinical vertebral fractures in older men. J Bone Miner Res 2014;29:2101-8. 